\title{
Aplikasi Monitoring Perangkat dan Aktivitas Pengguna pada Jaringan Menggunakan Protocol SNMP dan Squid Proxy
}

\author{
Danur Wijayanto1, ${ }^{*}$, Indra Waspada1 \\ ${ }^{1}$ Fakultas Sains dan Matematika, Departemen IImu Komputer/ Informatika \\ Universitas Diponegoro \\ (cooresponding author) danurwijayanto@gmail.com*)
}

\begin{abstract}
Management and Information Technology Services Division (UP2TI) is a unit in the Faculty of Science of Mathematics, University of Diponegoro engaged in the care and management of everything relating to information technology. UP2TI manage network devices such as routers, switches, servers, and access point in the FSM UNDIP. With a lot of number of networking devices need to manage , admin UP2TI got problem if the monitoring of network devices is done manually, simply relying based on client report and there is no system to monitor internet activity. A solution to these problems is creating a network monitoring system This application can also be referred to as the Network Management System that help system administrators to monitor and control the complex network SNMP is protocol TCP/IP that used as a protocol in the Network Management System. A system developed by using log squid proxy to determine the activities of internet users. The application development using waterfall method with PHP programming using Codelgniter framework and MySQL database management system. Once the development is completed, it followed by black-box testing. The result of this research is an application that help admin in monitoring devices and user activities on the network Diponegoro University Faculty of Science Mathematics.
\end{abstract}

Keyword- monitoring application, network management system (NMS), SNMP, Squid Proxy.

Intisari- Unit Pengelolaan dan Pelayanan Teknologi Informasi (UP2TI) adalah salah satu unit di Fakultas Sains Matematika Universitas Diponegoro yang bergerak di bidang pelayanan dan pengelolaan segala sesuatu yang berkaitan dengan teknologi informasi. UP2TI mengelola perangkat jaringan seperti router, switch, server, dan access point di FSM UNDIP. Dengan banyaknya perangkat jaringan yang dikelola, admin UP2TI mengalami kesulitan jika proses monitoring perangkat jaringan dilakukan secara manual yaitu hanya mengandalkan laporan dari client jika ada permasalahan pada jaringan dan juga belum ada sistem untuk memonitor aktifitas pengguna internet.Solusi atas permasalahan tersebut dengan membuat aplikasi monitoring jaringan. Aplikasi monitoring bisa juga disebut sebagai Network Management System yaitu suatu sistem yang berfungsi untuk membantu system administrator dalam memonitor dan mengontrol perangkat jaringan yang kompleks SNMP merupakan sebuah protocol aplikasi pada jaringan TCP/ IP yang dapat digunakan sebagai protocol dalam Network Management System.Aplikasi monitoring yang dikembangkan juga melakukan pembacaan log squid proxy untuk mengetahui aktivitas pengguna internet. Pengembangan aplikasi ini menggunakan metode waterfall dengan bahasa pemograman PHP dengan framework Codelgniter dan sistem manajemen basis data MySQL. Setelah pengembangan selesai dilakukan, dilanjutkan pengujian secara black-box. Hasil akhir dari penelitian ini adalah aplikasi yang memudahkan admin dalam memonitoring perangkat dan aktivitas pengguna pada jaringan Fakultas Sains Matematika Universitas Diponegoro.

Kata Kunci- aplikasi monitoring, network management system (NMS), SNMP, Squid Proxy.

\section{PENDAHULUAN}

Unit Pengelolaan dan Pelayanan Teknologi Informasi (UP2TI) adalah salah satu unit di Fakultas Sains Matematika Universitas Diponegoro yang bergerak di bidang pelayanan dan pengelolaan segala sesuatu yang berkaitan dengan teknologi informasi. UP2TI mengelola perangkat jaringan seperti router, switch, server, dan access point di FSM UNDIP. Dengan banyaknya perangkat jaringan yang dikelola, admin UP2TI mengalami kesulitan jika proses monitoring perangkat jaringan dilakukan secara manual yaitu hanya mengandalkan laporan dari client jika ada permasalahan pada jaringan.

UP2TI membutuhkan aplikasi monitoring jaringan yang berfungsi untuk mengetahui kondisi perangkat jaringan sehingga akan diketahui sumber masalah dalam jaringan, dan menampilkan aktifitas pengguna Internet. Selama ini belum ada sistem yang memantau kondisi perangkat jaringan di FSM Undip sehingga apabila terjadi masalah seperti 
server, router, dan switch mati admin masih mengandalkan laporan dari pengelola perangkat yang bersangkutan, dan juga belum ada sistem untuk memonitor aktifitas pengguna Internet. Untuk mengatasi permasalahan di atas maka diperlukan Network Management System (NMS).

NMS merupakan suatu sistem yang berfungsi untuk membantu system administrator dalam memonitor dan mengontrol perangkat jaringan yang kompleks.SNMP merupakan sebuah protocol aplikasi pada jaringan TCP/ IP yang dapat digunakan sebagai protocol dalam NMS. SNMP diperkenalkan pada tahun 1988 yang merupakan standard untuk mengelola peralatan Internet Protocol (IP). SNMP menyediakan operasi - operasi yang memungkingkan peralatan untuk dikelola secara jarak jauh seperti mematikan interface Ethernet, melakukan check kecepatan ethernet interface yang sedang beroperasi, memonitor suhu, dan memperingatkan kepada administrator jaringan jika suhu terlalu panas [1].

Beberapa penelitian mengenai NMS dan SNMP telah dilakukan sebelumnya, penelitian pertama menghasilkan aplikasi monitoring jaringan menggunakan SNMP yang memungkinkan administrator jaringan untuk memantau performa peralatan jaringan, untuk mendeteksi, mengisolasi dan recovery kesalahan dari peralatan jaringan, untuk mendapatkan statistik data yang diterima dan dikirimkan oleh perangkat, dan untuk mengontrol jaringan secara jarak jauh [2]. Penelitian kedua menghasilkan suatu aplikasi manajemen jaringan berbasis PHP dan SNMP yang menggunakan sistem operasi Linux Mandrive Limited Edition 2005. Aplikasi tersebut menginformasikan status link dari suatu segmen jaringan, sehingga admin jaringan akan diketahui sumber atau letak masalah dalam suatu jaringan tersebut [3]. Penelitian selanjutnya menghasilkan aplikasi monitoring jaringan berbasis web yang digunakan sebagai perantara untuk mengolah nilai SNMP yang disimpan dalam database MySQL yang kemudian digunakan untuk menampilkan informasi tentang kondisi jaringan yang meliputi availability perangkat dan trafik pada transport TCP [4].

Penelitian mengenai pembacaan aktivitas pengguna Internet menggunakan log squid proxy sebelumnya telah dilakukan oleh Zulfikri Rifqi Hakim yang menghasilkan aplikasi pembacaan log memanfaatkan file log squid web proxy sehingga dapat dimanfaatkan untuk analisis digital forensic saat terjadi cyber crime dan analisis statistik pengguna Internet di lingkungan FSM Undip [5] .

Berdasarkan penelitian yang ada, protocol SNMP dan pemanfaatan squid web proxy dirasa cukup efektif untuk digunakan dalam membangun sistem monitoring jaringan atau NMS. Maka dari itu, dalam penelitian ini, akan merancang aplikasi monitoring jaringan atau NMS menggunakan protocol SNMP dan squid web proxy yang akan digunakan untuk mempermudah admin dalam memonitor kondisi perangkat jaringan dan aktivitas pengguna Internet di lingkungan FSM Undip.

\section{TINJAUAN PUSTAKA}

Pada bab ini menyajikan teori yang digunakan dalam penelitian, yaitu Protocol SNMP dan NET-SNMP.

\section{A. Protocol SNMP}

NET-SNMP SNMP adalah standar protocol Internet untuk mengelola perangkat pada jaringan secara jarak jauh yang diperkenalkan pada tahun 1988. Protocol ini berada pada application layer. Beberapa perangkat mendukung protocol SNMP seperti routers, switches, dan servers. SNMP digunakan untuk melakukan monitoring terhadap kondisi dari routers, servers, dan perangkat jaringan lainnya yang mendukung protocol tersebut serta dapat menampilkan informasi seperti lalu lintas data yang keluar dan masuk interface dan temperature perangkat. [1].

SNMP menggunakan User Datagram Protocol (UDP) sebagai protocol transportasi untuk berkomunikasi antara manager dan agent karena sifatnya yang connectionless (tidak terjadi proses acknowledgement antara host pengirim dan penerima) sehingga mempunyai kecepatan komunikasi data yang tinggi. SNMP menggunakan UDP port 161 untuk mengirim dan menerima permintaan dan port 162 untuk menerima traps dari managed device.

Pada application layer, aplikasi SNMP (NMS atau manager) memutuskan apa yang akan dilakukan. Misalnya NMS mengirim SNMP request kepada agent, atau agent mengirim trap ke NMS. Layer aplikasi menyediakan informasi kepada user, seperti status dari port Ethernet Switch. Layer selanjutnya yaitu transport layer. Pada layer ini SNMP memanfaatkan protocol UDP untuk berkomunikasi. Pada layer Internet, SNMP menggunakan IP untuk menetukan tujuan packet. Layer terakhir yaitu Network Accesss dimana SNMP packet diterima oleh host tujuan berdasarkan MAC Address [1] . 


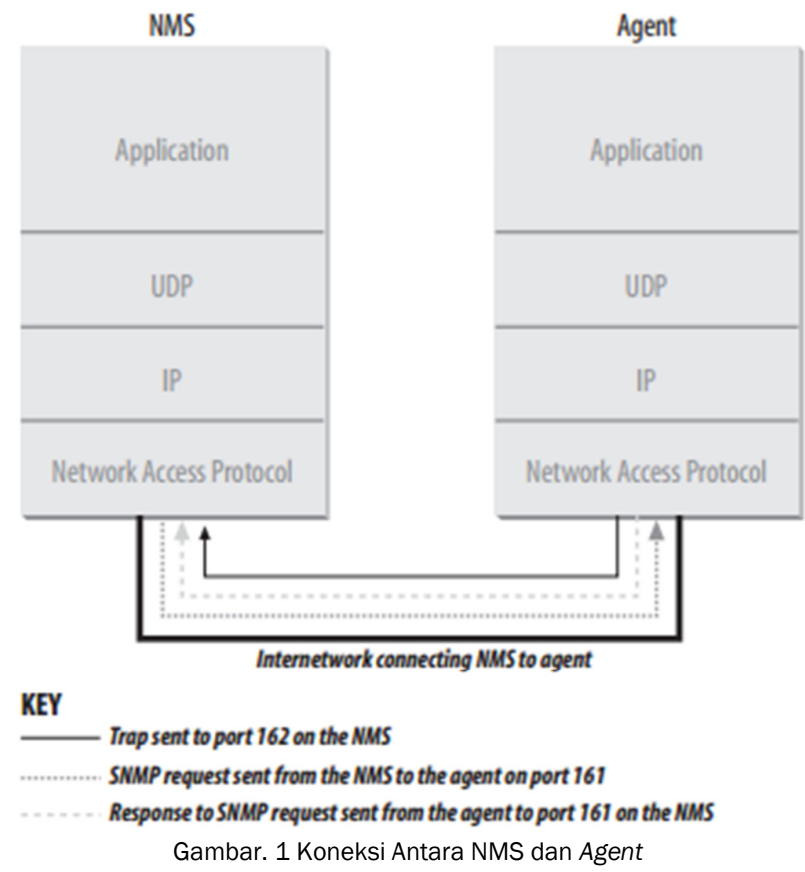

SNMP terdiri dari tiga elemen yaitu :

a. Manager

Manager adalah bagian dari SNMP selain agents. Sebuah manager merupakan sebuah server yang menjalankan beberapa macam perangkat lunak yang berfungsi melakukan pengelolaan jaringan. Manager bisa juga disebut sebagai Network Management System (NMS). Manager bertanggung jawab dalam berkomunikasi dengan agent pada perangkat jaringan yang dimonitor untuk mendapatkan informasi. [1].

b. Agent

Agent adalah perangkat lunak yang berjalan pada perangkat jaringan yang di-manage. Agent dapat berupa perangkat lunak terpisah (daemon), atau yang tergabung di dalam sistem operasi (CISCO IOS pada CISCO Router). Agent menyediakan informasi kepada NMS dengan menjaga track dari banyak operational aspect dari perangkat. Sebagai contoh, agent di router dapat menjaga track dari status setiap interface :interface mana yang aktif, dan interface mana yang mati. Ketika agent melihat ada masalah terjadi, agent akan mengirim trap kepada NMS [1].

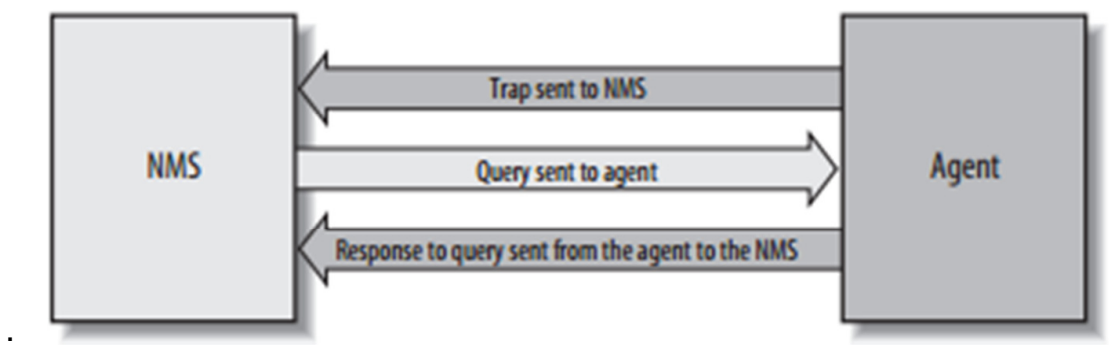

Gambar. 2 Interaksi Pesan Trap antara NMS dan Agent

c. Management Information Base (MIB)

MIB merupakan tempat penyimpanan informasi yang dimiliki oleh agen yang nantinya diakses oleh Network Management System (NMS). Informasi yang disimpan oleh MIB menggunakan diagram pohon dan menempatkan Object Identifier (OID) pada setiap node pohon. OID berupa integer yang dipisahkan oleh dots (.). 


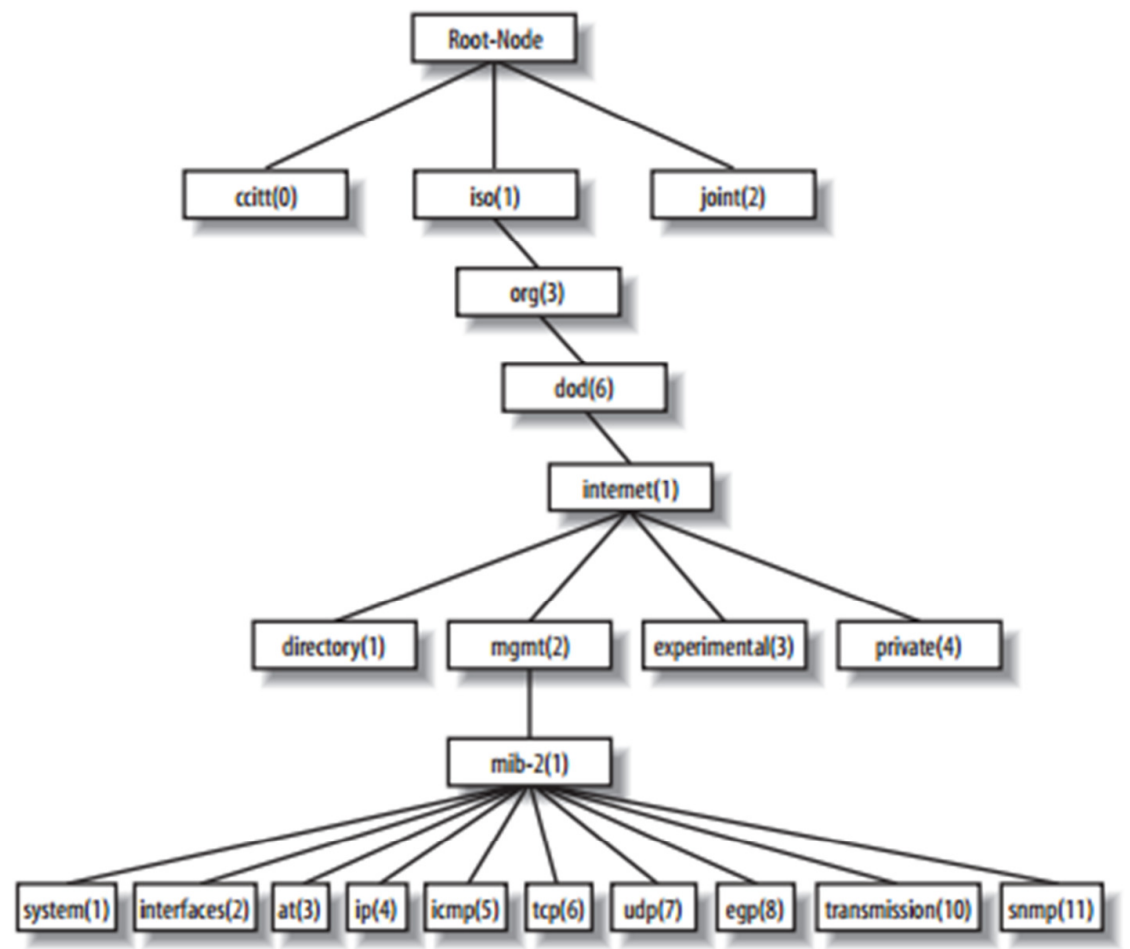

Gambar. 3 MIB Tree

Objek - objek informasi SNMP memperoleh kedudukan di bawah node mib-2(1). Untuk mengakses objek - objek tersebut maka harus dituliskan sesuai urutan node seperti yang dijelaskan pada tabel 1.

\begin{tabular}{|l|l|l|}
\hline \multicolumn{1}{|c}{$\begin{array}{c}\text { Subtree } \\
\text { name }\end{array}$} & \multicolumn{1}{c|}{ OID } & \multicolumn{1}{c|}{ Deskripsi } \\
\hline sistem & 1.3.6.1.2.1.1 & $\begin{array}{l}\text { Medifinisikan objek yang berhubungan } \\
\text { dengan sistem operasi, uptime, system } \\
\text { contact, dan system name }\end{array}$ \\
\hline interface & 1.3 .6 .1 .2 .1 .2 & Melacak status interface perangkat. \\
\hline at & 1.3 .6 .1 .2 .1 .3 & Alamat terjemahan \\
\hline ip & 1.3 .6 .1 .2 .1 .4 & $\begin{array}{l}\text { Melacak beberapa aspek dari IP, } \\
\text { termasuk IP Routing }\end{array}$ \\
\hline icmp & 1.3 .6 .1 .2 .1 .5 & Melacak ICMP error \\
\hline tcp & 1.3 .6 .1 .2 .1 .6 & Melacak koneksi TCP \\
\hline udp & 1.3 .6 .1 .2 .1 .7 & Melacak statistik UDP. \\
\hline egp & 1.3 .6 .1 .2 .1 .8 & $\begin{array}{l}\text { Melacak statistik dari Exterior Gateway } \\
\text { Protocol (EGP) dan menyimpannya } \\
\text { dalam EGP tabel }\end{array}$ \\
\hline transmission & 1.3 .6 .1 .2 .1 .9 & $\begin{array}{l}\text { Tidak ada objek yang didefinisikan pada } \\
\text { grub ini, tetapi ada beberapa perangkat } \\
\text { medefinisikan pada objek ini. }\end{array}$ \\
\hline \multicolumn{1}{|c|}{ snmp } & 1.3 .6 .1 .2 .1 .10 & $\begin{array}{l}\text { Mengukur kinerja SNMP seperti melacak } \\
\text { paket yang dikirim dan diterima }\end{array}$ \\
\hline
\end{tabular}

Protocol Data Unit (PDU) adalah format pesan yang digunakan oleh manager dan agent untuk mengirim dan menerima informasi. Jenis - jenis PDU dijelaskan pada table 2 berikut. 
Tabel 2 Format PDU

\begin{tabular}{|c|c|c|}
\hline Jenis & Versi SNMP & Keterangan \\
\hline get & SNMPv1 & $\begin{array}{l}\text { Permintaan untuk mendapatkan sebuah } \\
\text { informasi dari sebuah objek tertentu }\end{array}$ \\
\hline getnext & SNMPv1 & $\begin{array}{l}\text { Permintaan untuk mendapatkan sebuah } \\
\text { informasi dari sebuah objek tertentu } \\
\text { berikutnya }\end{array}$ \\
\hline getbulk & $\begin{array}{l}\text { SNMPv1, } \\
\text { SNMPv2 dan } \\
\text { SNMPV3 }\end{array}$ & $\begin{array}{l}\text { Permintaan untuk mendapatkan } \\
\text { informasi dari beberapa objek tertentu } \\
\text { sekaligus }\end{array}$ \\
\hline set & SNMPv1 & $\begin{array}{l}\text { Perintah untuk menuliskan sebuah } \\
\text { informasi ke sebuah objek tertentu }\end{array}$ \\
\hline getresponse & SNMPV1 & $\begin{array}{l}\text { Tanggapan Agnet SNMP terhadap } \\
\text { permintaan NMS. }\end{array}$ \\
\hline trap & SNMPv1 & $\begin{array}{l}\text { Pemberitahuan dari Agent SNMP kepada } \\
\text { NMS }\end{array}$ \\
\hline notification & $\begin{array}{l}\text { SNMPv1, } \\
\text { SNMPv2 dan } \\
\text { SNMPv3 }\end{array}$ & $\begin{array}{l}\text { Membakukan PDU format untuk SNMPv1 } \\
\text { traps }\end{array}$ \\
\hline inform & $\begin{array}{l}\text { SNMPv1, } \\
\text { SNMPv2, dan } \\
\text { SNMPV3 }\end{array}$ & $\begin{array}{l}\text { Pemberitahuan dari sebuah NMS kepada } \\
\text { NSM lain }\end{array}$ \\
\hline report & $\begin{array}{l}\text { SNMPv1, } \\
\text { SNMPv2, dan } \\
\text { SNMPv3 }\end{array}$ & $\begin{array}{l}\text { Tanggapan agent SNMP yang berisi } \\
\text { laporan statistik SNMP }\end{array}$ \\
\hline
\end{tabular}

\section{B. NET-SNMP}

Net-SNMP merupakan aplikasi open source yang mengimplementasikan SNMP. Dikembangkan di Universitas Carnegie Mellon (sekitar tahun 1995) dan Universitas California, Davis (antara tahun 1995 dan 2000). Sekarang dikembangkan oleh Net-SNMP development team (sejak 2000) yang disimpan di http://sourceforge.net/projects/net-snmp/. Net-SNMP menyediakan [6] :

1. Agen dengan MIB compiler yang dapat digunakan untuk mengembangkan MIB.

2. Library SNMP yang bisa digunakan utuk pengembangan selanjutnya.

3. Peralatan yang digunakan untuk memperoleh atau men-set informasi dari agen.

4. Peralatan untuk menghasilkan dan menangani SNMP traps dan mendukung SNMPv1, v2, dan v3.

Tabel 3 menampilkan deskripsi beberapa perintah di Net-SNMP dan PDU yang sesuai.

\begin{tabular}{|l|l|l|}
\hline \multicolumn{2}{|c|}{ Nama } & \multicolumn{1}{|c|}{ Tabel 3 Beberapa Perintah di Net-SNMP [6] } \\
\hline snmpget & Menerima nilai objek pada node. & GetRequest \\
\hline snmpset & Set nilai objek pada node & SetRequest \\
\hline snmpbulkget & $\begin{array}{l}\text { Mendapatkan banyak objek dalam satu } \\
\text { waktu dengan subtree yang berbeda }\end{array}$ & GetBulkRequest \\
\hline snmpwalk & $\begin{array}{l}\text { Menjelajahi semua objek dibawah } \\
\text { subtree MIB }\end{array}$ & GetNextRequest \\
\hline snmptrap & $\begin{array}{l}\text { Menggunakan permintaan TRAP untuk } \\
\text { mengeirim informasi ke network } \\
\text { manager. }\end{array}$ & Trap \\
\hline snmstatus & $\begin{array}{l}\text { Digunakan untuk menerima beberapa } \\
\text { statistik penting dari entitas jaringan }\end{array}$ & \\
\hline snmpnetstat & $\begin{array}{l}\text { Menampilkan nilai dari berbagai } \\
\text { informasi yang berhubungan dengan } \\
\text { jaringan menggunakan protocol SNMP }\end{array}$ & \\
\hline
\end{tabular}


C. SQUID

Squid merupakan open source caching proxy yang popular. Squid dapat bekerja sebagai proxy dan cache. Sebagai proxy, squid berperan sebagai perantara transaksi antara client dan server. Squid meenrima permintaan dari client, kemudian memproses dan meneruskannya ke server tujuan. Request tersebut dapat di log, ditolak, dan dimodifikasi sebelum diteruskan ke server tujuan. Sebagai cache, squid menyimpan konten web yang diterima untuk digunakan setelahnya.

Pada gambar 4 menunjukkan squid menerima permintaan HTTP dan HTTPS dari client, dan berkomunikasi dnegna beberapa protokol server. Secara umum, squid mengetahui bagaimana berkomunikasi dengan HTTP, FTP, dan Gopher servers. [7]

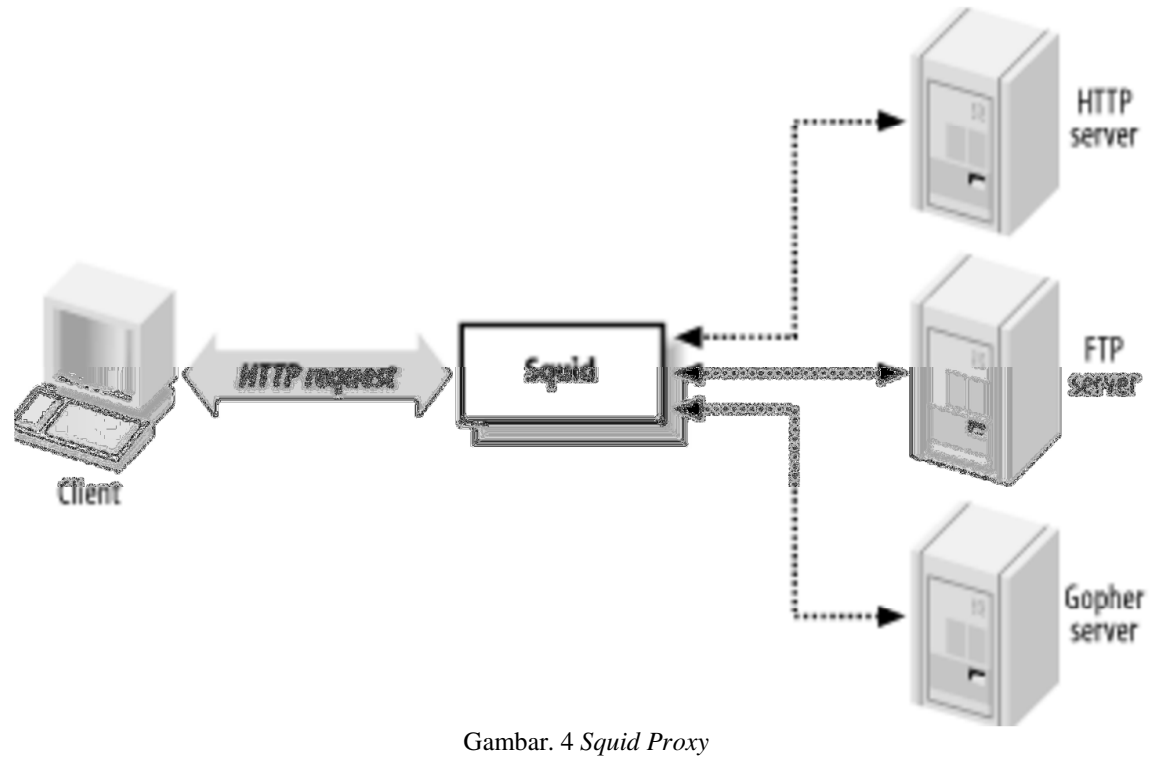

III. IMPLEMENTASI DAN CONTOH KASUS

Pada bab ini menyajikan implementasi pada penelitian ini berupa desain jarigan dan contoh kasus.

A. Desain Topologi

Gambar 4 memperlihatkan desain dari pengujian Aplikasi Monitoring Aktivitas dan Perangkat Jaringan.

Berikut perangkat hardware yang digunakan beserta spesifikasinya:

1. Server yang digunakan sebagai manager dengan spesifikasi :

- Intel i5-3220M 2.4 Ghz

- 4GB RAM DDR3

- 640GB HDD

- Ubuntu Desktop 14.04 LTS

- PHP versi 5.5

- Web Server Apache versi 2.4

- Net-SNMP versi 5.7.3

- Squid Proxy versi 3.1.20

2. Router Mikrotik Dinara untuk melakukan konfigurasi NAT pada squid proxy. 


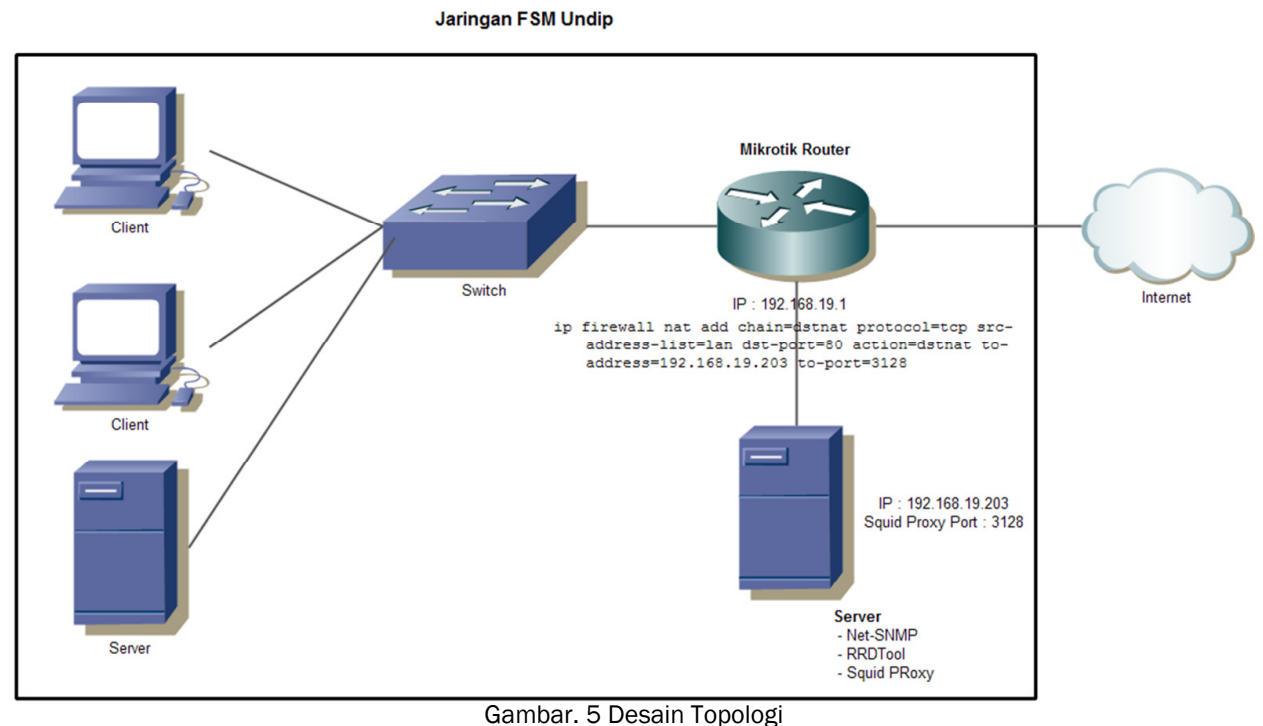

\section{B. Contoh Kasus dan Analisa Hasil}

Skenario 1

Kasus : Terjadi perubahan status perangkat

Hasil : Mengirimkan notifikasi email ke pengguna

Analisa :

Pada gambar 5 menunjukkan daftar semua perangkat yang telah didaftarkan pada aplikasi. Dalam kasus ini, perangkat yang digunakan yaitu Mikrotik Statistika. Dalam kondisi awal, Mikrotik Statistika mempunyai status UP. Dalam kasus ini, tiba - tiba perangkat Mikrotik Statistika mengalami perubahan status menjadi down. Daftar perangkat dapat dilihat pada gambar 6. Pada gambar tersebut dapat diketahui telah terjadi perubahan status perangkat Mikrotik Statistika menjadi Down. Selain status pada daftar perangkat berubah, aplikasi juga akan mengirim notifikasi ke email pengguna. Isi dari email dapat dilihat pada gambar 7. Dalam gambar tersebut dapat dilihat nama perangkat yang mengalami perubahan status, status lama, status baru dan waktu terjadinya perubahan status pada perangkat tersebut.

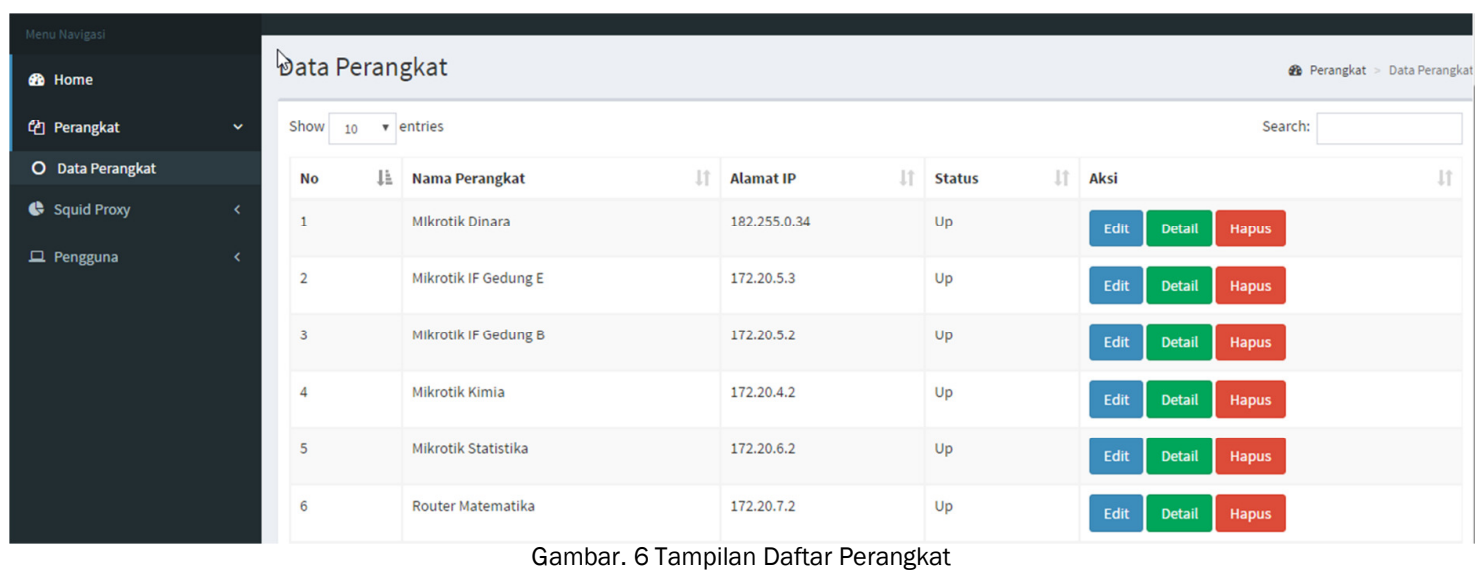




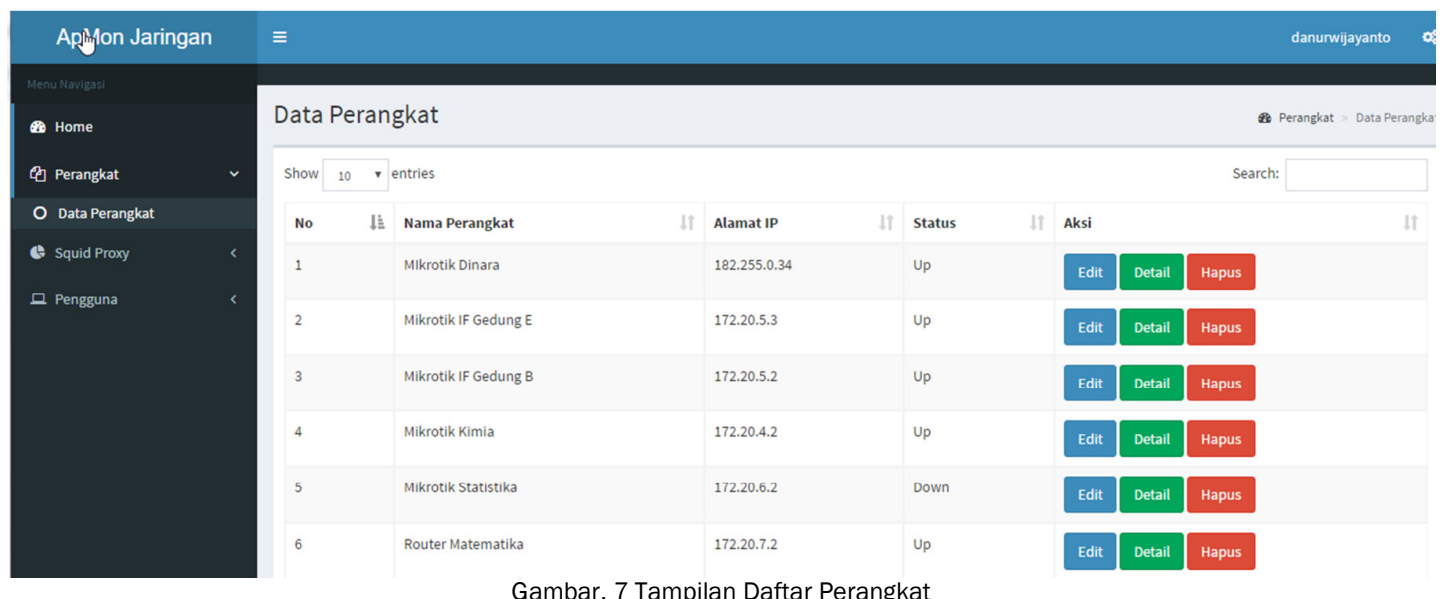

Gambar. 7 Tampilan Daftar Perangkat

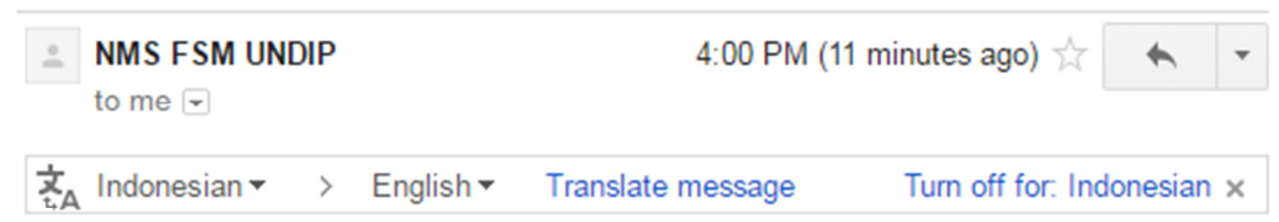

Terjadi Perubahan Status Perangkat Pada :

\begin{tabular}{|l|l|l|l|l||}
\hline No & \multicolumn{1}{|c|}{ Perangkat } & Status Lama & Status Baru & \multicolumn{1}{c|}{ Waktu } \\
\hline \hline 1 & Mikrotik Statistika & Up & Down & 2016-08-28 16:00:06 \\
\hline
\end{tabular}

Terjadi Perubahan Status Interface Pada :

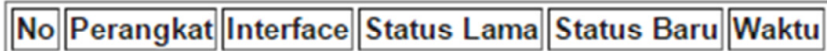

Gambar. 8 Notifikasi Email

Skenario 2

Kasus : Pencarian data log squid

Hasil : Menampilkan statistik hasil pencarian

Analisa :

Untuk melakukan pencarian, pengguna harus memasukkan parameter pencarian pada form yang telah disediakan. Parameter - parameter tersebut adalah interface, waktu awal dan waktu akhir. Tampilan form dapat dilihat pada gambar 8. Setelah semua parameter pencarian telah dimasukkan kemudian pengguna mengakses tombol cari. Setelah itu aplikasi akan menampilkan informasi nama situs, dan jumlah pengakses dalam bentuk grafik yang dapat dilihat pada gambar 9. 


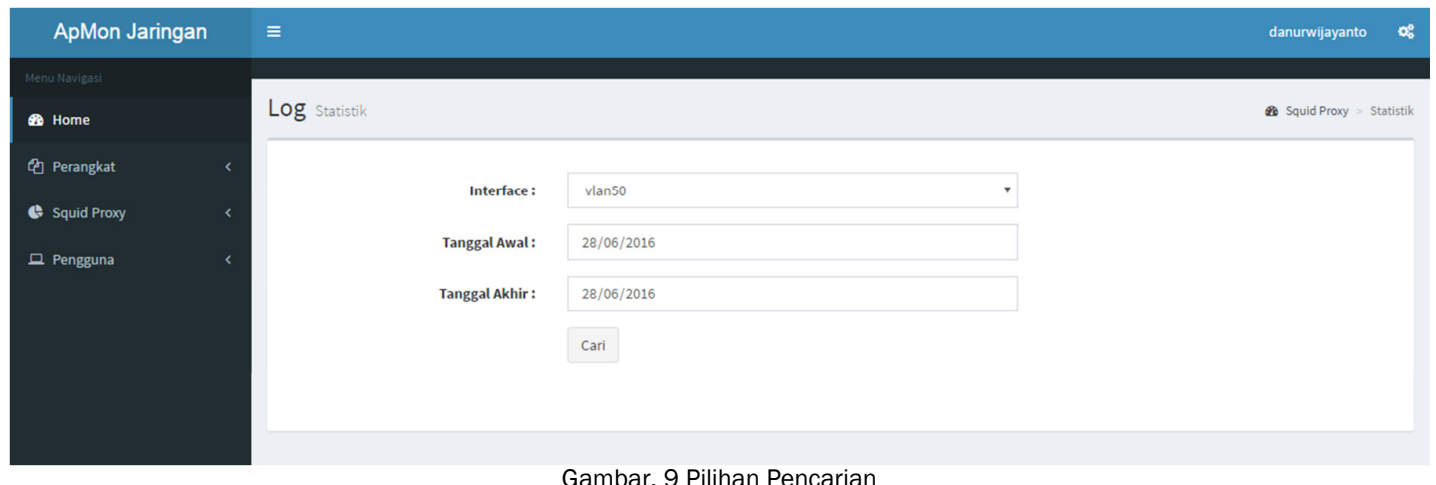

Gambar. 9 Pilihan Pencarian

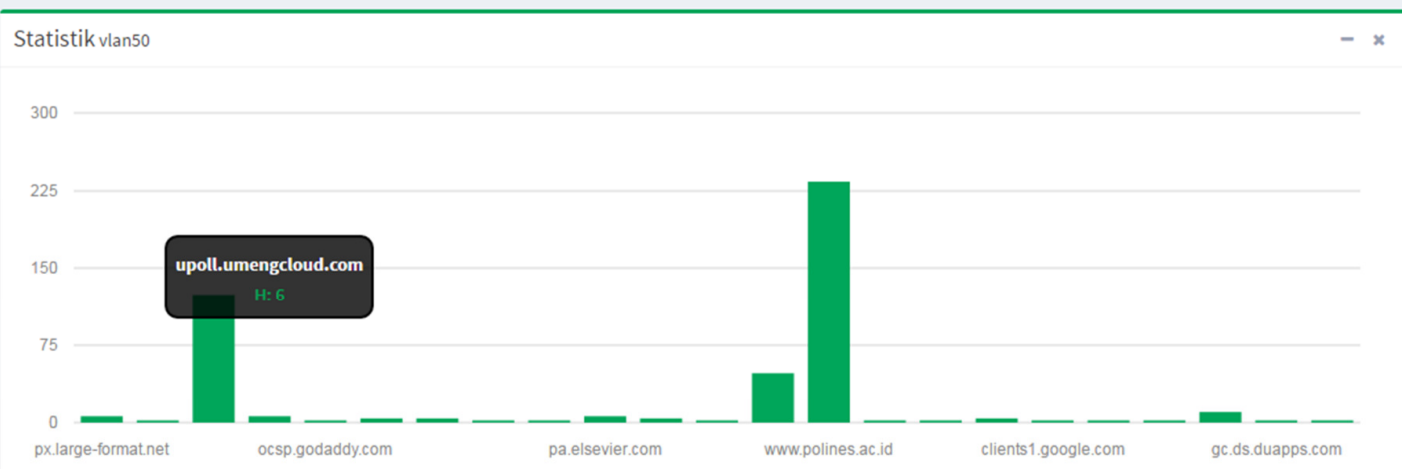

Gambar. 10 Hasil Pencarian

IV. KESIMPULAN

Kesimpulan yang dapat diambil dari hasil penelitian ini adalah :

a. Menghasilkan aplikasi monitoring perangkat dan pengguna menggunakan protocol SNMP dan Squid Proxy yang diimplementasikan di Fakultas Sains dan Matematika Universitas Diponegoro.

b. Aplikasi melakukan pengecekan status perangkat dan interface setiap 3 menit.

c. Aplikasi mendukung protokol SNMP versi 1, 2 dan 3.

d. Aplikasi dapat membantu admin me-monitoring perangkat jaringan dan memantau aktifitas pengguna Internet.

e. Aplikasi dapat mengetahui informasi perangkat seperti status interface, waktu keadaan up, jumlah traffic masuk dan keluar, IP Address, subnet mask, dan jumlah interface pada perangkat yang dikelola

f. Aplikasi dapat menyimpan traffic masuk dan keluar pada interface perangkat yang disimpan dalam RRDTool.

g. Aplikasi dapat mengetahui asal pengguna jaringan Internet dengan memanfaatkan IP asal log squid dan data interface perangkat yang dikelola. 


\section{REFERENSI}

[1] Douglas R Mauro and Kevin J Schmidt, Essential SNMP 2nd Edition, 2nd ed. Uniteed States of America: 0`Reilly Media, 2005.

[2] Abubucker Samsudeen Shaffi and Mohanned Al-Obaidy, "Managing Network Component Using SNMP," International Journal of Scientific Knowledge, vol. 2, 2012.

[3] Sri Puji Utami, Surya Agustian, and Iman Fauzi Aditya Sayogo, "Perancangan Online Network Monitoring Berbasis PHP dan SNMP," SNATI 2006, 2006.

[4] Reza Pradikta, Achmad Affandi, and Eko Setijadi, "Rancang Bangun Aplikasi Monitor Jaringan dengan Menggunakan SNMP," Jurnal Teknik Pomits, 2013.

[5] Zulfikri Hakim Rifqi, "Sistem Pembacaan Log Penggunaan Internet Menggunakan SQUID PROXY," skripsi, Departemen IImu Komputer/ Informatika, Universitas Diponegoro, Semarang, 2013.

[6] Ying-Dar Lin, Ren-Hung Hwang, and Fred Baker, Computer Networks An Open Source Approach. New York: McGraw-Hill, 2012.

[7] Duane Wessels, Squid: The Definitive Guide. USA: O'Reilly Media, 2004. 